\title{
Diagnóstico imuno-histopatológico da paratuberculose subclínica em bovinos no estado do Rio de Janeiro ${ }^{1}$
}

\author{
Elise M. Yamasaki ${ }^{2}$, Marilene de Farias Brito ${ }^{3}$, Douglas McIntosh ${ }^{4}$, Alexandre Galvão ${ }^{5}$, \\ Tiago C. Peixoto ${ }^{6}$ e Carlos Hubinger Tokarnia ${ }^{7}$
}

\begin{abstract}
Yamasaki E.M., Brito M.F., McIntosh D., Galvão A., Peixoto T.C. \& Tokarnia C.H. 2013. [Imuno-histopatologic diagnosis of subclinic bovine paratuberculosis in the state of Rio de Janeiro.] Diagnóstico imuno-histopatológico da paratuberculose subclínica em bovinos no estado do Rio de Janeiro. Pesquisa Veterinária Brasileira 33(12):14271432. Curso de Pós-Graduação em Ciências Veterinárias, Universidade Federal Rural do Rio de Janeiro, Seropédica, RJ 23890-000, Brazil. E-mail: elise_my@yahoo.com.br

The early and specific diagnosis of paratuberculosis remains a challenge due to the low sensitivity of the currently available laboratory tests and also because of variations in the immune response towards infection with Mycobacterium avium subsp. paratuberculosis. Globally this disease causes significant economic losses, primarily in dairy cattle, owing to the chronic nature of the infection. Paratuberculosis has been described in a number of Brazilian states and from a diversity of domestic ruminant species clearly demonstrating that the disease is present in the country and highlighting the requirement for the development of diagnostic techniques for confirmation of infection and for epidemiological analyses. The aim of this study was to characterize the anatomo-histopathological and immunohistochemical findings in the bowel and mesenteric lymph nodes of assymptomatic cattle, derived from paratuberculosis positive herds located in state of Rio de Janeiro, Brazil. Macroscopic examination during necropsy revealed nonspecific changes including reddening of the gut mucosa, increased volumes for the Peyer's patches and mesenteric lymph nodes and in some case dilation and whitening of the mesenteric lymphatic vessel. Histopathology revealed granulomatous infiltration, occasionally with the formation of giant cells in the jejunal and ileal mucosa or sub-mucosa, and/or in the cortical region of the mesenteric lymph nodes, in 32 of the 52 cattle examined. Tissue sections from these animals were subjected to Ziehl-Neelsen staining, but the presence of acid-fast bacilli was not observed. Subsequent analysis, employing genus specific immunohistochemisty for Mycobacterium, revealed areas of immunoreactivity in sections prepared from a total of six animals. The results of this investigation highlighted the value of histopathology and particularly immunohistochemistry as tools for the diagnosis of subclinical paratuberculosis.
\end{abstract}

INDEX TERMS: Paratuberculosis, Johne's disease, cattle, immunohistochemistry, pathology, Brazil.

RESUMO.- 0 diagnóstico precoce e específico da paratuberculose ainda é um desafio. Isto pode estar associado à baixa sensibilidade dos testes laboratoriais e ou à variação da

\footnotetext{
${ }^{1}$ Recebido em 12 de agosto de 2013.

Aceito para publicação em 9 de outubro de 2013.

${ }^{2}$ Curso de Pós-Graduação em Ciências Veterinárias, Universidade Federal Rural do Rio de Janeiro (UFRRJ), Rodovia BR-465 Km7, Seropédica, RJ 23890-000, Brasil. *Autor para correspondência: elise_my@yahoo.com.br

${ }^{3}$ Departamento de Epidemiologia e Saúde Pública, Instituto de Veterinária, UFRRJ, Seropédica, RJ.

${ }^{4}$ Depto Parasitologia Animal, Instituto de Veterinária, UFRRJ, Seropédica, RJ.
}

resposta imunológica frente à infecção por Mycobacterium avium subsp. paratuberculosis. Mundialmente, é uma enfermidade que causa importantes prejuízos econômicos, em

\footnotetext{
${ }^{5}$ Médico Veterinário, Doutorado em Ciências Veterinárias, UFRRJ, Seropédica, RJ.

${ }^{6}$ Departamento de Anatomia, Patologia e Clínicas Veterinárias, Escola de Medicina Veterinária e Zootecnia, Universidade Federal da Bahia (UFBA), Avenida Adhemar de Barros 500, Ondina, Salvador, BA 40170110, Brasil.

${ }^{7}$ Departamento de Nutrição Animal e Pastagem, Instituto de Zootecnia, UFRRJ, Seropédica, RJ.
} 
especial, à bovinocultura leiteira, devido ao caráter crônico da infecção. No Brasil, a paratuberculose já foi descrita em diversas espécies de ruminantes domésticos e em vários estados, o que demonstra que a enfermidade está presente em território nacional e há a necessidade de elaboração de técnicas de diagnóstico para a confirmação da infecção. 0 objetivo deste trabalho foi caracterizar os achados anátomo-histopatológicos e imuno-histoquímicos em intestino e linfonodos mesentéricos de bovinos assintomáticos, provenientes de rebanhos positivos para paratuberculose localizados no estado do Rio de Janeiro, Brasil. 0 estudo macroscópico revelou alterações inespecíficas tais como áreas avermelhadas na mucosa do intestino, aumento do volume das placas de Peyer e dos linfonodos mesentéricos, além disso, observou-se que vasos linfáticos mesentéricos estavam dilatados e esbranquiçados. Do total de 52 vacas leiteiras avaliadas, a histopatologia revelou infiltração granulomatosa, por vezes com formação de células gigantes multinucleadas, em mucosa e ou submucosa de jejuno, íleo e em linfonodos mesentéricos, principalmente na região cortical, em 32 animais. Estes bovinos foram submetidos à coloração de Ziehl-Neelsen cujo teste não demonstrou reação positiva, no entanto, quando analisados pelo teste imunohistoquímico para Mycobacterium spp. observou-se imunorreação em 6 animais. Desta forma, a histopatologia e imunohistoquímica pode ser uma importante ferramenta para diagnóstico da paratuberculose subclínica.

TERMOS DE INDEXAÇÃO: Paratuberculose, doença de Johne, bovinos, imuno-histoquímica, patologia, Brasil.

\section{INTRODUÇÃO}

A paratuberculose, também chamada de doença de Johne, é causada por Mycobacterium avium subsp. paratuberculosis (Map); afeta principalmente ruminantes e é responsável por prejuízos econômicos importantes na produção animal (Timms et al. 2011). 0 período de incubação da doença de Johne é longo e irregular; a maioria dos animais infectados não apresenta os sinais clínicos característicos da enfermidade ao longo de sua vida (Behr \& Collins 2010) e pode eliminar, intermitentemente, a micobactéria no ambiente, através das fezes. 0 diagnóstico precoce e específico da paratuberculose ainda é um desafio (Timms et al. 2011, Mon et al. 2012) relacionado, em parte, à baixa sensibilidade dos testes laboratoriais existentes (Stabel 2010, Timms et al. 2011, OIE 2013), o que contribui para a ineficiência das medidas de controle no rebanho. 0 interesse pelo estudo do Map se deve, também, à sua possível associação com a doença de Crohn em seres humanos (Nakase et al. 2011, Van-Kruiningen 2011, Retamal et al. 2011, Chiodini et al. 2012, Singh \& Gopinath 2012).

Em levantamento bibliográfico realizado sobre a ocorrência da paratuberculose no Brasil, verificou-se que a enfermidade já foi relatada em 11 estados, o que evidencia a sua importância epidemiológica no país (Yamasaki et al. 2013). Diante disso, observa-se a necessidade de elaboração de ferramentas de diagnóstico confiáveis para detecção de animais subclínicos dentro do rebanho e, consequentemente, proporcionar melhorias nas medidas de controle em rebanhos positivos para paratuberculose.
O objetivo deste trabalho foi caracterizar os achados anátomo-histopatológicos e imuno-histoquímicos em intestino e linfonodos mesentéricos de bovinos assintomáticos, provenientes de propriedades positivas para paratuberculose no estado do Rio de Janeiro.

\section{MATERIAL E MÉTODOS}

A partir da confirmação do diagnóstico de paratuberculose em rebanho bovino (por meio de informações e dados obtidos através do histórico, exames anátomo-histopatológicos e imuno-histoquímico, isolamento de Map a partir de fezes e de raspado de mucosa intestinal e por PCR IS900 e F57), foi realizado um estudo imuno-histopatológico em intestino e linfonodos mesentéricos de vacas destinadas ao abate sem sinais clínicos da enfermidade, com o intuito de identificar animais na fase assintomática da infecção.

\section{Coleta de fragmentos de intestino e linfonodos mesentéricos}

Entre 2007 e 2012 foram avaliadas 52 vacas leiteiras assintomáticas provenientes de dois rebanhos positivos para paratuberculose localizados na região sul do estado do Rio de Janeiro.

Do Rebanho A, localizado no município de Rio Claro, RJ, foram estudados 50 vacas, as quais foram enviadas para abate por variados motivos, tais como mastite recidivante, desordens reprodutivas, principalmente ausência de cio, distúrbios locomotores, pododermatites e fratura em membros. Durante as visitas periódicas ao frigorífico para acompanhamento do abate foram realizadas avaliação macroscópica e coleta de fragmentos de diferentes seções do intestino (duodeno, jejuno, íleo, válvula íleo-cecal, ceco e cólon) e de linfonodos mesentéricos.

Do Rebanho B, localizado no município de Barra Mansa, RJ, foram avaliadas duas vacas, as quais foram necropsiadas na propriedade e, igualmente, coletados fragmentos de diversas seções de intestino e de linfonodos mesentéricos.

\section{Histopatologia}

Após a avaliação macroscópica do trato intestinal, os fragmentos foram coletados em frascos separados, identificados e fixados em formol a $10 \%$ neutralizado com carbonato de cálcio e processados pelos métodos usuais para análise histológica no Laboratório de Histopatologia, do Projeto Sanidade Animal (PSA) do Convênio Embrapa/UFRRJ; em seguida, foram incluídos em parafina, cortados a $5 \mu \mathrm{m}$ e corados pela Hematoxilina-Eosina (HE). Os fragmentos que apresentaram lesões granulomatosas foram corados pela técnica de Ziehl-Neelsen (ZN) (Luna 1968) para evidenciação de bacilos álcool-ácido resistentes (BAARs) e, em seguida, submetidos ao teste imuno-histoquímico (IHQ) para Mycobacterium spp. Controles positivos e negativos foram utilizados a cada processamento.

\section{Teste imuno-histoquímico}

As secções foram cortadas em micrótomo a $5 \mu \mathrm{m}$ e aderidas a lâminas de vidro, previamente tratadas com silano (3-aminopropyl-triethoxysilane, Sigma-Aldrich, cat.A3648). Em seguida, foram desparafinadas em xilol, lavadas em álcool e hidratadas em água destilada. A peroxidase endógena tecidual foi inativada com $\mathrm{H}_{2} \mathrm{O}_{2}$ a $3 \%$ em solução aquosa por 30 minutos. Após a lavagem com água destilada, fêz-se a reativação antigênica com protease XIV (Sigma, cat.P5147), na concentração de $0,2 \mathrm{mg} / \mathrm{ml}$, por $30 \mathrm{minu}-$ tos à $37^{\circ} \mathrm{C}$. Novamente foi realizada lavagem com água destilada, e em seguida as lâminas foram tratadas com leite em pó desnatado (Molico) a 5\% em solução aquosa por 30 minutos a temperatura ambiente e, lavadas novamente em água destilada. Depois, as lâminas foram incubadas "overnight" a $6^{\circ} \mathrm{C}$ (em geladeira) com anticorpo primário contra Mycobacterium spp. (GeneTex, cat.20905) 
numa diluição de 1:500 em "phosphate buffer saline" (PBS), pH 7,4. No dia seguinte, após a lavagem das lâminas em água destilada, utilizou-se o método da biotina-estreptavidina peroxidase (kit comercial LSAB Dako, cat.0690) e a revelação das reações foi realizada com o cromógeno AEC (Aminoetil-carbamazole, Dako, cat. K3461), de acordo com as instruções do fabricante. As lâminas foram contracoradas com hematoxilina de Harris não alcoólica e, em seguida montadas com lamínula em meio aquoso (Faramount Aqueous Mounting Medium, Dako cod.S3025). A avaliação foi realizada em microscópio óptico (Olympus BX41TF). A cada processamento foram utilizados controles positivo e negativo e, também, fragmentos com e sem anticorpo primário.

\section{RESULTADOS}

\section{Macroscopia}

O estudo macroscópico revelou alterações inespecíficas na mucosa de diversas porções do intestino delgado e grosso dos bovinos assintomáticos, de ambos os rebanhos que consistiram em áreas avermelhadas de intensidade leve a moderada (Fig.1); no intestino delgado de alguns bovinos as placas de Peyer estavam mais proeminentes e notou-se leve espessamento da parede. Os linfonodos mesentéricos de alguns animais apresentaram aumento de volume em graus leve a moderado e os vasos linfáticos mesentéricos estavam dilatados e esbranquiçados.

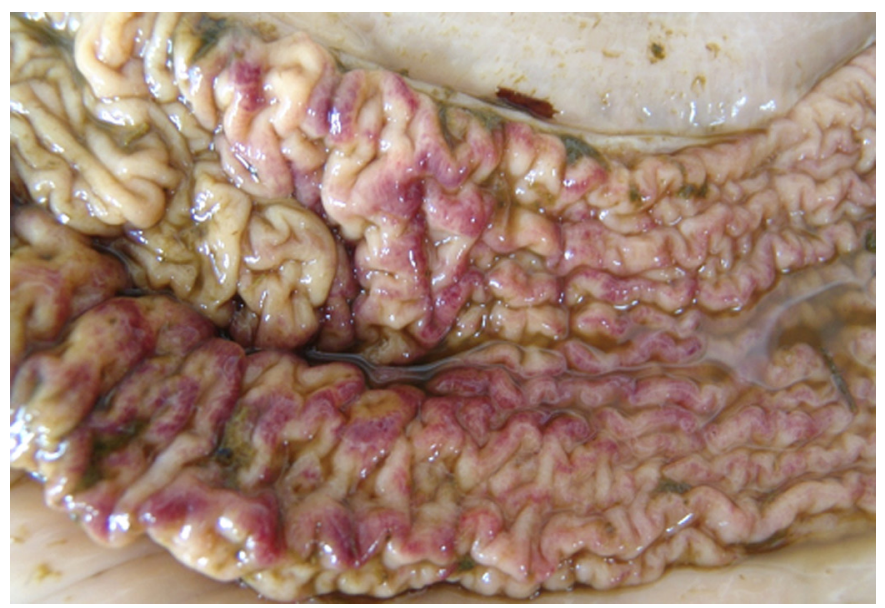

Fig.1. Aspecto enrugado e áreas avermelhadas em mucosa de intestino delgado de bovino assintomático, proveniente de rebanho positivo para paratuberculose, localizado no município de Rio Claro, RJ.

\section{Histopatologia}

Rebanho A. Das 50 vacas, 31 animais apresentaram inflamação granulomatosa em jejuno, íleo (Fig.2) e/ou linfonodo mesentérico (Fig.3); a intensidade das lesões variou entre leve e moderada. Em 19 vacas não foram observadas alterações histológicas compatíveis com a infecção. A coloração de ZN não revelou presença de BAARs nos fragmentos analisados.

Rebanho B. Dos dois animais avaliados, apenas um bovino apresentou leve infiltração por macrófagos epitelioides em mucosa e submucosa do intestino delgado; não foram evidenciados BAARs nas secções analisadas.

No intestino grosso não foram observadas lesões compatíveis com paratuberculose nos animais de ambos os rebanhos.

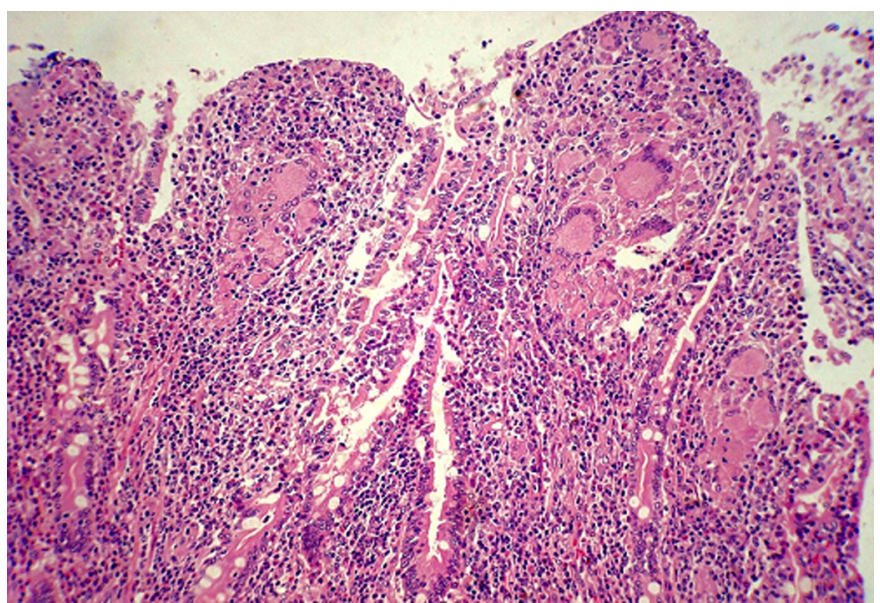

Fig.2. Infiltração granulomatosa e formação de células gigantes de Langhans no ápice das vilosidades de mucosa do jejuno, de bovino assintomático, proveniente de rebanho positivo para paratuberculose, localizado no município de Rio Claro, RJ. HE, obj.16x.

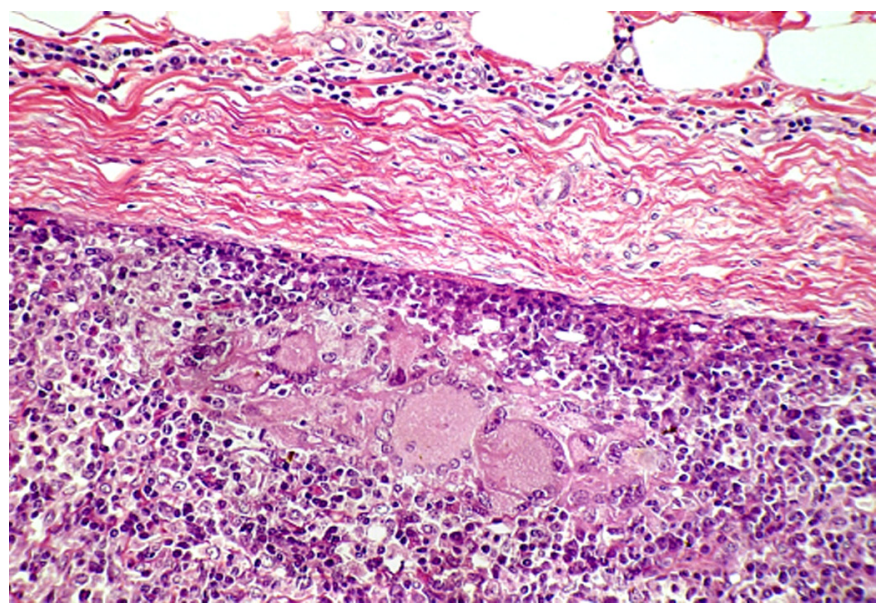

Fig.3. Células gigantes de Langhans na região cortical de linfonodo mesentérico de bovino assintomático, proveniente de rebanho positivo para paratuberculose, localizado no município de Rio Claro, RJ. HE, obj.16x.

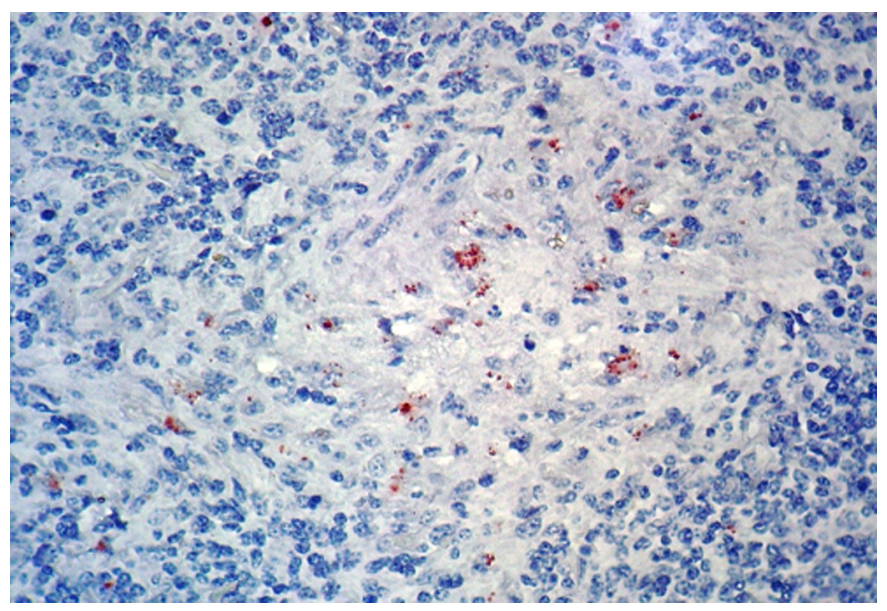

Fig.4. Imunomarcação positiva para Mycobacterium sp. em linfonodo mesentérico de bovino assintomático, proveniente de rebanho positivo para paratuberculose, localizado no município de Rio Claro, RJ. Imuno-histoquímica, Método biotina-estreptavidina peroxidase, cromógeno AEC, obj.16x. 


\section{Imuno-histoquímica}

Rebanho A. Do total de 50 animais, 6 vacas apresentaram marcação positiva para Mycobacterium spp. de intensidade leve a moderada em jejuno, íleo e/ou linfonodo mesentérico (Fig.4).

Rebanho B. Os dois bovinos assintomáticos não apresentaram imunorreação ao teste de IHQ, apesar de se ter observado lesão granulomatosa no intestino delgado e linfonodo mesentérico de um dos animais.

\section{DISCUSSÃO}

A detecção precoce de animais infectados por Mycobacterium avium subsp. paratuberculosis é de importância primordial para o sucesso de programas controle (OIE 2013). Uma das principais características da doença de Johne que contribui para a disseminação da infecção em um rebanho é que os sinais clínicos se manifestam somente quando o animal encontra-se no estágio terminal da doença e, nesta fase, elimina grande quantidade de Map no ambiente através das fezes diarreicas. A detecção de indivíduos assintomáticos e posterior abate, pode contribuir para a melhoria das medidas de controle e ainda, limitar a disseminação e manutenção da infecção no rebanho (OIE 2013). No entanto, os testes diagnósticos existentes não são sensíveis o suficiente para detectar animais na fase assintomática ou subclínica da infecção (OIE 2013).

À macroscopia, os bovinos deste estudo apresentaram leve espessamento da parede do intestino delgado; tal achado pode estar relacionado ao início do processo granulomatoso causado por Map; no entanto, deve-se considerar a importância de se diferenciar o espessamento das alças intestinais devido à multiplicação do agente infeccioso, daquele que ocorre no "post-mortem" associado ao "rigor-mortis" (Driemeier et al. 1999). Além disso, o avermelhamento observado na mucosa intestinal, aumento do volume das placas de Peyer e em linfonodos mesentéricos, poderiam, também, estar associados à exposição à helmintos e a inúmeros antígenos, comumente presentes na luz intestinal, acarretando em processos inflamatórios inespecíficos (Jubb et al. 2007).

Lesões histológicas sugestivas de infecção por Map foram observadas em alguns bovinos assintomáticos estudados e, sua presença, foi confirmada pelo teste imuno-histoquímico. Estes animais tinham entre 4 e 10 anos de idade, no entanto, não foi possível estimar o período de incubação, a quantidade de Map ingerida, se estes animais se infectaram quando jovens ou na idade adulta, ou ainda, se eram resistentes ao desenvolvimento de lesões acentuadas. Pesquisadores têm observado a resistência/susceptibilidade genética à tuberculose e paratuberculose em várias espécies de ruminantes (Mackintosh et al. 2011, Korou et al. 2010, Osterstock et al. 2010, Reddacliff et al. 2005, Mackintosh et al. 2000). Tais parâmetros poderiam auxiliar no delineamento de estratégias de controle em rebanhos infectados, a fim de minimizar as possibilidades de ingestão de Map, selecionar indivíduos resistentes à infecção pelo agente, ou ainda, estabelecer manejo diferenciado na propriedade.

Do total de 52 bovinos avaliados neste estudo, 32 bovinos apresentaram lesões granulomatosas de intensidade leve a moderada em jejuno, íleo e/ou linfonodos mesentéricos, sugestivas de paratuberculose. Lesões similares foram reproduzidas experimentalmente em bovinos, após um mês da administração oral de Map (Payne \& Rankin 1961a, 1961b) e após 150 dias da infecção (Larsen et al. 1975); os autores relataram que a histopatologia revelou presença de células gigantes solitárias no ápice das vilosidades e em linfonodos mesentéricos. À semelhança desses autores, também encontramos leve a moderada infiltração granulomatosa na mucosa e submucosa do intestino delgado e nos linfonodos mesentéricos. Infecção experimental com Map e visualização de alterações histológicas provocadas pelo processo inflamatório granulomatoso, também foram relatadas em outras espécies de ruminantes (Clark et al. 2010).

Um inconveniente das técnicas de diagnóstico anátomo-patológico é que, em alguns casos, há a necessidade de eutanásia dos animais; no entanto, tem sido empregada a técnica de biópsia de íleo e de linfonodo mesentérico para confirmação da doença de Johne (Buergelt \& Ginn 2000, McConnel et al. 2004, Imirzalioglu et al. 2011), inclusive no estágio subclínico da infecção (Buergelt \& Ginn 2000). 0 diagnóstico por meio de biópsia em animais de produção é recomendado, principalmente, naqueles indivíduos de alto valor zootécnico; deve-se levar em consideração a relação custo-benefício, pois esta técnica exige conhecimento e equipamentos especializados (McConnel et al. 2004). Buergelt \& Ginn (2000) realizaram a biópsia para diagnosticar a paratuberculose em ruminantes selvagens mantidos em zoológicos. Além disso, no Brasil, biópsia de tecido retal foi realizada em bubalino, cujo tecido revelou imunomarcação para M. avium (Dalto et al. 2012). Ainda, vale ressaltar que, em nosso estudo, não foram observadas alterações histológicas no cólon das vacas assintomáticas estudadas.

\section{Coloração de ZN}

Neste estudo, secções intestinais e de linfonodos mesentéricos com infiltração granulomatosa e, inclusive, com formação de células gigantes de Langhans, não revelaram BAARs. Este teste apresenta baixo custo operacional e é de fácil execução, porém a sua sensibilidade é baixa e evidencia apenas micobactérias com a parede celular íntegra; a não visualização de BAARs nas amostras analisadas pode estar associada à presença de bactérias degradadas ou com envoltório celular modificado (esferoplastos) (Olsen et al. 2002, Martinson et al. 2008).

\section{Teste de imuno-histoquímica}

Do total de 52 bovinos assintomáticos avaliados neste estudo, 32 apresentaram infiltração granulomatosa sugestiva de paratuberculose em intestino delgado e/ou linfonodo mesentérico; BAARs não foram evidenciados em nenhum fragmento analisado. No entanto, ao teste de IHQ, seis bovinos apresentaram marcação positiva para antígenos de Mycobacterium spp. o que demonstra sensibilidade elevada deste teste em relação à técnica de ZN. Este achado é similar ao descrito por Massone et al. (1990) e Coetzier \& Tustin (2004), que relatam a maior sensibilidade da IHQ quando comparado às técnicas para detecção de BAARs, principalmente em casos contendo poucas micobactérias. 
Maior acurácia da IHQ também foi descrita por Brees et al. (2000) e Paolicchi et al. (2001), em que os autores utilizaram anticorpo espécie-específico contra Map, conferindo, além de maior sensibilidade, maior especificidade ao teste. Ainda, Delgado et al. (2009) relataram um estudo comparativo entre duas metodologias para detecção de Map, os testes de IHQ e de "in situ hibridization" (ISH) em fragmentos em que não foram evidenciados BAARs. Apesar de ambos os testes mostrarem-se positivos, os autores relataram que a IHQ foi mais vantajosa em relação ao ISH, pois além da facilidade na visualização da marcação e da intensidade de células positivas, a técnica é de fácil execução. A desvantagem da ISH estava relacionada à dificuldade na identificação da hibridização positiva, pois, além desta técnica ser mais laboriosa, exige maior esforço, tempo e conhecimento do patologista para a leitura das lâminas. Portanto, os autores relataram que os resultados da IHQ foram mais satisfatórios em relação ao ISH, e este por sua vez, apresentou melhores resultados em relação à técnica de ZN (Delgado et al. 2009). Ao contrário disso, Jeyanathan et al. (2006) observaram maior sensibilidade da técnica de ZN quando comparado ao ISH. Outro estudo realizado em caprinos infectados com Map também demonstrou alta percentagem de positivos na IHQ em relação à coloração de ZN e ao cultivo bacteriano (Thorensen et al. 1994) diferentemente do descrito por Martinson et al. (2008) em que relataram elevada sensibilidade do cultivo bacteriano quando comparado à coloração de $\mathrm{ZN}$ e IHQ.

Do total de 32 bovinos que apresentaram infiltração granulomatosa em intestino e ou linfonodo mesentérico sugestivos de paratuberculose, o teste de IHQ revelou apenas 6 animais positivos para a presença de antígenos de Mycobacterium spp. este resultado pode estar associado ao fixador de tecido utilizado. 0 formol é um fixador de baixo custo que inibe a autólise, preserva a arquitetura do tecido e destrói a maioria dos agentes infecciosos. No entanto, uma das suas principais desvantagens é a formação de "cross-linking" das cadeias de aminoácidos (Eltoum et al. 2001, Ramos-Vara 2005), ou seja, promove um "entrelaçamento" das moléculas de proteínas, o que pode alterar, fragmentar ou "esconder" os epítopos e inibir as reações no teste de IHQ (Werner et al. 2000, Ramos-Vara 2005). Neste estudo, apesar das reativações antigênicas realizadas para induzir a exposição dos epítopos e otimizar a marcação (Shi et al. 1998, Ramos-Vara 2005), não foram observados resultados positivos na maioria dos fragmentos de intestino delgado e de linfonodos mesentéricos com infiltração granulomatosa. Adicionalmente, deve-se considerar que a quantidade e distribuição de Map nas amostras analisadas poderiam estar em níveis não detectáveis pelo protocolo adotado, visto que, a ausência de marcação não significa ausência do antígeno no tecido (Ramos-Vara et al. 2008). Ainda, acreditamos que, animais assintomáticos podem não apresentar infiltração granulomatosa difusamente distribuída ao longo do trato intestinal e nos linfonodos mesentéricos e, desta forma, ter-se coletado áreas do tecido sem alterações.

As reações cruzadas com outras micobactérias não podem ser totalmente excluídas; neste estudo, a positividade do teste de IHQ para Mycobacterium spp. juntamente com o histórico do rebanho e as características histológicas das lesões granulomatosas nos tecidos analisados foram compatíveis com a infecção por Map. Infecções intestinais com M. bovis e M. avium são consideradas raras em bovinos e a morfologia dos granulomas causados por estes agentes são caracterizadas principalmente por necrose caseosa (Jubb et al. 2007, McGavin \& Zachary 2007), características estas não observadas nos fragmentos deste estudo. É interessante mencionar que, em pequenos ruminantes lesões decorrentes da resposta imune contra Map pode causar necrose caseosa associado à infiltração granulomatosa (Menendez 1990).

Apesar da IHQ não ser uma técnica rotineiramente utilizada nos laboratórios de diagnóstico veterinário, é um teste valioso, pois possibilita a visualização do antígeno no contexto da lesão histológica, o que facilita a identificação de possíveis imunorreações falso-positivas (Webster et al. 2010) e, confere ao teste, maior sensibilidade e especificidade diagnóstica. Neste estudo, o teste de IHQ apresentou maior sensibilidade em relação à coloração de ZN em fragmentos de intestino e linfonodo mesentérico, fixados em formol e incluídos em parafina, e verificou-se que a IHQ pode ser uma importante ferramenta laboratorial para confirmação da infecção por Map, principalmente em casos contendo poucos BAARs, o que enriquece os métodos convencionais de diagnóstico histopatológico. Além disso, esta metodologia apresenta vantagens em situações onde não há disponibilidade de material para cultivo bacteriano e possibilita a realização de estudos retrospectivos.

\section{CONCLUSÕES}

É possível observar alterações histológicas decorrentes da infecção por Map em jejuno, íleo e em linfonodos mesentéricos de bovinos assintomáticos.

A detecção de animais infectados com Map por métodos imuno-histopatológios pode ser uma importante ferramenta para o diagnóstico da paratuberculose subclínica.

Agradecimentos.- Ao Professor Marcos Gomes, da Faculdade de Veterinária da Universidade Federal do Rio Grande do Sul, por ter cedido amostras de Map utilizadas para a padronização da PCR e ao CNPQ pela concessão de bolsa de doutorado.

\section{REFERÊNCIAS}

Behr M.A. \& Collins D.M. 2010. Paratuberculosis: organism, disease, control. CAB International, Cambridge. 375p.

Brees D.J., Reimer S.B., Cheville N.F., Florance A. \& Thoen C.O. 2000. Immunohistochemical detection of Mycobaterium paratuberculosis in formalin-fixed, paraffin-embedded bovine tissue sections. J. Vet. Diagn. Invest. 12:60-63.

Buergelt C.D. \& Ginn P.E. 2000. The histopathologic diagnosis of subclinical Johne's disease in North American Bison (Bison bison). Vet. Microbiol. 77:325-331.

Chiodini R.J., Chamberlin W.M., Sarosiek J. \& McCallum R.W. 2012. Crohn's disease and the mycobacterioses: a quarter century later. Causation or simple association? Crit. Rev. Microbiol. 38(1):52-93.

Clark R.G., Griffin J.F.T. \& Mackintosh C.G. 2010. Johne's diasease caused by Mycobacterium avium subsp. paratuberculosis infection in red deer (Cervus elaphus): an histopathological grading system and comparison of paucibacillary and multibacillary disease. N.Z. Vet. J. 58(2):90-97. 
Clark R.G., Griffin J.F.T. \& Mackintosh C.G. 2011. Modification to histopathological lesion severity score in red deer (Cervus elaphus) affected by Johne's disease. N.Z. Vet. J. 59(5):261-262.

Coetzer J.A.W. \& Tustin R.C. 2004. Infectious Disease in Livestock. $2^{\text {nd }}$ ed. Oxford University Press, Cape Town. 2352p.

Dalto A.C., Bandarra P.M., Pavarini S.P., Boabaid F.M., Bitencourt A.P.G., Gomes M.P., Chies J., Driemeier D. \& Cruz C.E.F. 2012. Clinical and pathological insights into Johne's disease in buffaloes. Trop. Anim. Health Prod. 44:1-5.

Delgado F., Etchechoury D., Gioffré A., Paolicchi F., Blanco-Viera F., Mundo S. \& Romano M.I. 2009. Comparison between two in situ methods for Mycobacterium avium subsp. paratuberculosis detection in tissue samples from infected cattle. Vet. Microbiol. 134:383-387.

Driemeier D., Cruz C.E.F., Gomes M.J.P., Corbellini L.G., Loretti A.P. \& Colodel E.M. 1999. Aspectos clínicos e patológicos da paratuberculose em bovinos no Rio Grande do Sul. Pesq. Vet. Bras. 19(3/4):109-115.

Eltoum I., Fredenburgh J., Myers R.B. \& Grizzle W.E. 2001. Introduction to the theory and practice of fixation of tissues. J. Histotechnol. 24:173190.

Imirzalioglu C., Dahmen H., Hain T., Billion A., Kuenne C., Chakraborty T. \& Domann E. 2011. Highly specific and quick detection of Mycobacterium avium subsp. paratuberculosis in feces and gut tissue of cattle and humans by multiple real-time PCR assays. J. Clin. Microbiol. 49(5):18431852.

Jeyanathan M., Alexander D.C., Turenne C.Y., Girard C. \& Behr M.A. 2006. Evaluation of in situ methods used to detect Mycobacterium avium subsp. paratuberculosis in samples from patients with Crohn's disease. J. Clin. Microbiol. 44(8):2942-2950.

Jubb K.V.F., Kennedy P.C. \& Palmer N.C. 2007. Pathology of Domestic Animals. Vol.1-3. $5^{\text {th }}$ ed. Saunders Elsevier.

Korou L.M., Liandris E., Gazouli M. \& Ikonomopoulos J. 2010. Investigation of the association of the SLC11A1 gene with resistance/sensitivity of goats (Capra hircus) to paratuberculosis. Vet. Microbiol. 144:353-358.

Larsen A.B., Merkal R.S. \& Cutlip R.C. 1975. Age of cattle as related to resistance to infection with Mycobacterium paratuberculosis. Am. J. Vet. Res. $35: 255-257$

Luna L.G. 1968. Manual of Histologic Staining Methods of the Armed Forces Institute of Pathology. $3^{\text {rd }}$ ed. McGraw-Hill, Sydney. 258p.

Mackintosh C.G., Clark R.G., Tolentino B., DeLisle G.W., Liggett S. \& Griffin J.F.T. 2011. Immunological and pathological responses of red deer resistant or susceptible genotypes, to experimental challenge with Мycobacterium avium subsp. paratuberculosis. Vet. Immunol. Immunopathol. 143:131-142.

Mackintosh C.G., Qureshi T., Waldrup K., Labes R.E., Dodds K.G. \& Griffin J. 2000. Genetic resistance to experimental infection with Mycobacterium bovis in red deer (Cervus elaphus). Infect. Immun. 68:1620-1625.

Martinson S.A., Hanna P.E., Ikede B.O., Lewis J.P., Miller L.M., Keefe G.P. \& McKenna S.L.B. 2008. Comparison of bacterial culture, histopathology and immunohistochemistry for the diagnosis of Johne's disease in culled dairy cows. J. Vet. Diagn. Invest. 20:51-57.

Massone A.R., Martín A.A., Ibargoyen G.S. \& Gimeno E.J. 1990. Immunohistochemical methods for the visualization of Mycobacterium paratuberculosis in bovine tissues. J. Vet. Med. 37(4):251-253.

McConnel C.S., Churchil R.C., Richard M.M., Corkhill C.M., Reddacliff L.A. \& Whittington R.J. 2004. Surgical method for biopsy of terminal ileum and mesenteric lymph nodes of sheep for detection of Mycobacterium avium subsp. paratuberculosis. Aust. Vet. J. 82(3):149-151.

McGavin M.D. \& Zachary J.F. 2007. Pathologic Basis of Veterinary Disease. Mosby Elsevier, Missouri. 388p.

Menendez L.A.C. 1990. Ovis: tratado de patologia y produccion ovina. Luzán, Madrid.

Mon M.L., Viale M., Baschetti G., Pinedo F.A., Gioffre A., Traveria G., Willemsen P., Bakker D. \& Romano M.I. 2012. Search for Mycobacterium avium subspecies paratuberculosis antigens for the diagnosis of paratuberculosis. Vet. Med. Intern. Doi:10.1155/2012/860362.

Nakase H., Tamaki H., Matsura M., Chiba T. \& Okazaki K. 2011. Involvement of Mycobacterium avium subspecies paratuberculosis in TNF-a production from macrophage: possible link between MAP and immune response in Crohn's disease. Inflamm. Bowel Dis. 17(11):E140-142.

OIE 2013. Paratuberculosis (Johne's disease). Disponível em <http:// www.oie.int/fileadmin/Home/eng/Health_standards/tahm/2.01.11_ PARATB.pdf $>$ Acesso em 6 jun. 2013.

Olsen I., Sigurdardottir O.G. \& Djonne B. 2002. Paratuberculosis with especial reference to cattle: a review. Vet. Quart. 24:12-28.

Osterstock J.B., Sinha S., Seabury C.M. \& Cohen N.D. 2010. Effect of classifying disease states in genetic association studies for paratuberculosis. Prev. Vet. Med. 95:41-49.

Paolicchi F.A., Vagnozzi A., Morsella C.G., Verna A.E., Massone A.R., Portiansky E.L. \& Gimeno J. 2001. Paratuberculosis in red deer (Cervus elaphus): an immunohistochemical study. J. Vet. Med. 48:313-320.

Payne J.M. \& Rankin J.D. 1961a. A comparison of the pathogenesis of experimental Johne's disease in calves and cows. Res. Vet. Sci. 2:175-179.

Payne J.M. \& Rankin J.D. 1961b. The pathogenesis of experimental Johne's disease in calves. Res. Vet. Sci. 2:167-174.

Ramos-Vara J.A. 2005. Technical aspects of immunohistochemistry. Vet. Pathol. 42:405-426.

Ramos-Vara J.A., Kiupel M., Baszler T., Bliven L., Brodersen B., Chelack B., Czub S., Del Piero F., Dial S., Ehrhart E.J., Graham T., Manning L., Paulsen D., Valli V.E. \& West K. 2008. Suggested guidelines for immunohistochemical techniques in veterinary diagnostic laboratories. J. Vet. Diagn. Invest. 20:393-413.

Reddacliff L.A., Beh K., McGregor H. \& Whittington R.J. 2005. A preliminary study of possible genetic influences on the susceptibility of sheep to Johne's disease. Aust. Vet. J. 83:435-441.

Retamal P., Beltrán C., Abalos P., Quera R. \& Hermoso M. 2011. Possible association between Mycobacterium avium subsp. paratuberculosis infection and Crohn's disease. Revta Med. Chil. 139(6):794-801.

Shi S.R., Cote R.J., Chaiwun B., Young L.L., Shi Y., Hawes D., Chen T. \& Taylor C.R. 1998. Standardization of immunohistochemistry based on antigen retrieval technique for routine formalin fixed tissue sections. Appl. Immunohistochem. Mol. Morphol. 6:89-96.

Singh S. \& Gopinath K. 2012. Mycobacterium avium subspecies paratuberculosis and Crohn's regional ileitis: How strong is association? J. Lab. Physicians 3(2):69-74.

Stabel J.R. 2010. Immunology of paratuberculosis, infection and disease, p.230-243. In: Berhs M.A. \& Collins D.M. (Eds), Paratuberculosis: organism, disease, control. CAB International, Cambridge.

Thorensen O.F., Falk K. \& Evensen O. 1994. Comparison of immunohistochemistry, acid fast staining and cultivation for detection of Mycobacterium paratuberculosis in goats. J. Vet. Diagn. Invest. 6:195-199.

Timms V.J., Gehringer M.M., Mitchell H.M., Daskaloupous G. \& Neilan B.A. 2011. How accurately can we detect Mycobacterium avium subsp. paratuberculosis infection? a review. J. Microbiol. Meth. 85:1-8.

Van-Kruiningen H.J. 2011. Where are the weapons of mass destruction: the Mycobacterium paratuberculosis in Crohn's disease? J. Crohn's Colitis 5(6):638-644.

Webster J.D., Miller M.A., Dusold D. \& Ramos-Vara J. 2010. Effects of prolonged formalin fixation on the immunohistochemical detection of infectious agents in formalin-fixed, paraffin-embedded tissues. Vet. Pathol. 47(3):529-535.

Werner M., Chott A., Fabiano A. \& Battifora H. 2000. Effect of formalin tissue fixation and processing on immunohistochemistry. Am. J. Surg. Pathol. 24(7):1016-1019.

Yamasaki E.M., Brito M.F., Mota R.A., McIntosh D. \& Tokarnia C.H. 2013. Paratuberculose em ruminantes no Brasil: uma revisão. Pesq. Vet. Bras. 33(2):127-140. 